\title{
ACADEMIC AND PROFESSIONAL TRAINING OF TEACHERS.
}

II.

THERE is another implication regarding the relation between subject-matter and corresponding method in the combination course, in the course composed chiefly of academic subjects and special methods, which will bear looking into; and that is the implication that method has not a content of its own which is derived from and applicable to all subject-matters. According to the view under criticism, you have, on the one hand, in the training course so many academic subjects which match up with subjects now being taught in the schools, and on the other hand you have an equal number of special methods corresponding. The academic subjects are supposed to give the content, the filling, to the mind of the student ; the special methods are to aid him in readapting this content to the minds of prospective pupils. The academic subjects are there chiefly on sufferance, to make up for deficiencies in the scholastic training of students; and yet the special methods are naught apart from the corresponding subject-matters. It is a case of the Kantian dualism - content without form is blind, and form without content is empty. It creates a deadlock, under an assumed reciprocity. It marks time without getting anywhere.

The difficulty flows from the narrow and shortsighted assumption that the courses in a training school must simply reflect or match courses that are being taught in the schools. Acting on such an assumption, a training school would follow rather than lead in the educational procession. Instead of being the point in the whole educational system where pressing needs for improvement are most keenly reported, felt, interpreted, and even anticipated, where the means are at hand for working out and testing experimentally new and better programs and methods in response to these needs, thus becoming a center of helpful 
influence and rational direction, such a training school tends to become a mere recruiting station for "the rank and file," who, like the British soldiers grimly characterized by Carlyle, "fight without knowledge of war," if not "without fear of death."

But a training school is surely more than a recruiting station. If it is fulfilling its function and justifying its existence, a training school is the place where naturally and as a matter of course the conscious direction of educational progress, the scientific working out and experimental testing of educational reforms, should be more active, critical, and effective than at any other point in the entire system; not because the training school is in any sense cut loose from the rest of the system, a favored spot where exotic ideals may bloom in luxuriance unmolested by the hard, practical conditions that obtain elsewhere, but because in the deepest educational sense it is bound up with the whole system, bound up with the intellectual and moral resources of its past and with the possibilities of its immediate future; beeause it is the system most conscious at this point of all its parts and of their relations, and of its life as a working whole. The ideal training school is a continual rebirth or renaissance of education. It is desirable, no doubt, that a training school should include what is called a "model school," where there can be displayed the best ways of doing the thing that has been done and is being done; but it is also desirable that it should include an experimental school which should aim to work out, test, and verify ways of doing still better things. Thus the training school becomes the point at which the whole educational system is most conscious of itself, the point at which it is explicitly engaged in educating itself.

All this carries with it the necessity of a conscious gathering up, of a concept, of the educational situation as a working whole, a systematic gathering up in the sense that, like physiology, it has to do with a system. This is method in the larger sense of the word-call it theory, philosophy, psychology, or history of education, or all combined, though I do not mean to imply that it would be desirable to ignore customary distinctions; method, not in the sense of an empty framework to be filled in with a more 
or less alien content, but method in the sense of principles of construction, principles that are inherent in the materials themselves - the growing mind and the institutions and vocations of community life. Such a gathering up and studying of educational principles has a content, a subject-matter of its own, which is nothing less than education itself. In that respect it is an academic subject like political enconomy, for example, or chemistry. It is also the core of the training-school situation; not an afterthought, save in the sense that all thought is afterthought; not an external thing, save in the sense that the working use of principles, or concepts, make one more sensitive, discriminating, alive to things externally perceived; not formal, save in the sense that reconstructs, anticipates, more adequate and economical forms of organization.

It is plainly inconceivable that courses in educational theory should in any sense supersede courses in special methods and technique. On the contrary, the latter should find themselves freed and reinforced. The task of carrying the whole thing is lifted from courses in special methods and in technique, which now may become technical in the true sense of the term, points of application to, of contact with, the more immediate realities of teaching. They represent the academic and theoretical work focused upon the near view, and so in turn do they contribute to the perspective of the whole.

To sum up the matter as it appears from the point of view of this discussion: In addition to the inevitable courses in subjectmatter and in special methods and technique in the training of teachers, there is a demand, growing out of the present conflict and confusion, for the more explicit recognition of two important principles, one of which looks to the development of the individual teacher, the other to the development of the whole educational situation.

I. The first of these principles is a direct contribution from the most advanced academic methods of training teachers now in vogue, methods which carry with them the implication that a student must first be a learner, an inquirer, an independent investigator, in some degree, before he is deemed qualified to 
teach. If this contribution be accepted by the training school, it carries with it the practical corollary that students in the training school should be afforded ample opportunities to elect advanced academic courses in subjects for which they have a natural interest and sufficient qualification, and which are likely to give scope and direction to the inquiring, experimental, or constructive tendencies of the growing mind. Such opportunities, such electives, belong as much to a training school as clinics to a medical school, or moot courts to a law school, and for precisely the same reason, namely, that they afford intimate, firsthand experience in the fundamental realities and processes of the profession, which in the case of the training school are summed up in the process of learning; not learning in the scholastic sense of acquiring more information or mechanical expertness, but in the sense of developing latent capacities of thought and action through the exercise of these capacities. The graduate of a training school who has not had some recent first-hand experience in the most genuine forms of learning is no better off than the graduate of a medical school who has never witnessed an operation, or the graduate of a law school who has never taken part in a moot-court trial; in fact, he may be considerably worse off.

2. With reference to the whole educational situation there is becoming apparent a clearer recognition of the strategic position of the training school. It is difficult to see how a training school can justify its existence to its supporters if it is really nothing more than a trade school. Such a conception would inevitably react against those who would seem to be favored most by it, namely, the teachers themselves, by swelling the ranks of pattern-trained apprentices beyond the point of assimilation. Neither can a training school hope to receive more than a chance "social sanction" if it goes to the other extreme and proceeds to develop, on the basis of arbitrary, personal dicta, a detailed pedagogic program as a pretty complete reaction from established methods. Nor is a hand-to-mouth compromise between two such extremes desirable, or likely to receive "social sanction." 
The training school is coming to occupy a strategic, a controlling position in educational affairs along with the development of education as an experimental social science. The training school is coming to be the laboratory of that science. As a laboratory, it sustains the same reciprocal relation to the more theoretical interests, on the one hand, and to the more immediately practical interests, on the other, that any scientific laboratory sustains - a laboratory of chemistry, say-to mathematics and theoretical chemistry, on the one hand, and to commercial and manufacturing interests, on the other.

There is a sense in which all practice is experimental, in so far as the carrying of ideas into effect involves an element of risk, of uncertainty. Again, practice is rarely completely satisfactory, even when it safely reaches the end proposed to itself. It would seem, in education, at least, as if the less uncertain, the less experimental, any form of practical procedure is, the more unsatisfactory as a means of true education it is likely to be ; and, on the other hand, the more satisfactory and ideal some newly proposed form of procedure appears to be, the greater the element of uncertainty in putting it into effect. I will not try to illustrate this, for I believe the experience of almost any teacher would readily furnish illustrations. Now, the true laboratory begins wherever the uncertain, problematic points in everyday practice are reported, or sensed, most keenly; where they are interpreted, or diagnosed, most intelligently, that is, in the light of underlying principles; and where better ways of overcoming the difficulties are worked out as ideals most comprehensively, and not merely worked out as ideals, but tested experimentally under the most favorable conditions. All this, in the case of a laboratory of education, would naturally involve a theory of education with its psychological, ethical, and logical aspects. Moreover, what is perhaps more to the point, it would naturally be the locus of the training school; for it almost goes without saying that the place in the educational system or organism that is most alive to all phases of the educational situation, most alive to all tendencies in the educational movement, is surely the place where the best training in education is to be had, whether general or specialized. 
Possibly this sounds like reasoning in a circle. Earlier in this paper I was maintaining that the training school is naturally the point in the educational system where reconstruction is going on in the most rapid and controlled way; and now I am saying that such a point is naturally the locus of the training school. Still, if these statements be true, I do not see that they can be other than complementary, or other than two aspects of the same truth. It is, after all, simply a question as to whether educators shall be educated by education; a question as to whether they shall be a conscious part of that reflection, prophecy, and verification, of that continual experiment, by which education, not without toil, pain, and conflict, perennially educates and renews itself.

The University of Chicago

Willard C. Gore. School of Education. 